\title{
Estrutura e distribuição espacial da regeneração natural de canjerana em Floresta Estacional Decidual
}

\author{
Anna Paula Lora Zimmermann¹, David Fagner de Souza e Lira ${ }^{1}$, Frederico Dimas Fleig ${ }^{1}$ \\ ${ }^{1}$ Universidade Federal de Santa Maria, Centro de Ciências Rurais, Av. Roraima, n 1.000, CEP 95.105-900, Santa Maria, RS, Brasil
}

"Autor correspondente:

zimmermann-a@hotmail.com

Termos para indexação:

Padrão de dispersão

Índices de dispersão

Dispersão zoocórica

Index terms:

Dispersion pattern

Dispersion indexes

Zoochoric dispersion

\begin{abstract}
Resumo - Este trabalho objetivou analisar o padrão de distribuição espacial de uma população de Cabralea canjerana (Vell.) Mart. em fase de regeneração natural em um fragmento de Floresta Estacional Decidual no Município de Silveira Martins, RS. Para tais análises, foram mensurados os indivíduos da espécie que apresentavam altura $\geq 30 \mathrm{~cm}$, em 77 unidades amostrais alocadas de forma contígua na área. Para analisar a forma de dispersão da espécie foram utlizados os índices de Morisita, Payandeh e Fracker e Brischle. A estrutura foi analisada por meio dos parâmetros densidade e frequência absolutas e histograma de distribuição em classes de altura. De acordo com os índices de dispersão, a espécie encontra-se de forma agregada. Os altos valores de densidade e frequência ratificam a importância da espécie na estrutura da floresta.
\end{abstract}

\section{Structure and spatial distribution of natural regeneration of canjerana in Deciduous Forest}

\section{Introdução}

Cabralea canjerana (Vell.) Mart., da família Meliaceae, é típica da Floresta Estacional Decidual no Sul do Brasil, considerada por Backes \& Irgang (2002) uma das espécies mais valiosas do Brasil, por apresentar madeira de alto valor econômico e durabilidade. Entretanto, ainda são poucas as informações conhecidas sobre a Cabralea canjerana e as referências, quando existentes, não tratam com clareza, sendo que ainda existem algumas lacunas quanto ao conhecimento do comportamento ecológico da espécie (Schüssler, 2006).

A análise dos padrões de distribuição espacial é uma das ferramentas mais eficazes para compreender o comportamento de fenômenos que ocorrem nas formações florestais (Anjos et al., 1998). A análise espacial de uma floresta não pode identificar diretamente quais processos atuam na comunidade, mas pode levar a inferências sobre quais processos são mais importantes (Coomes et al., 1999). Muitas hipóteses partem do 
pressuposto que indivíduos próximos no espaço e no tempo estão mais ligados e mais sujeitos a influências dos mesmos processos locais (Legendre \& Fortin, 1989).

Para Capretz (2004), o nível de organização espacial das árvores dentro do povoamento é influenciado por diversos processos ecológicos e características próprias de cada ambiente. Assim, conhecer o padrão espacial das espécies-chave é de suma importância, pois pode fornecer informações sobre ecologia, subsidiar e definir estratégias de conservação, auxiliar em processos de amostragem ou, simplesmente, demonstrar a estrutura espacial de uma espécie (Anjos et al., 1998).

Embora haja estudos relacionados à Floresta Estacional Decidual, a exploração intensiva e a falta de pesquisas voltadas à ecologia e dinâmica das espécies que compõem a comunidade promovem riscos à continuidade desta formação florestal. Diante disto, estudos sobre a regeneração natural são essenciais para a elaboração e aplicação correta dos planos de manejo para o aproveitamento racional e permanente dos recursos florestais (Rayol et al., 2006).

Assim, este trabalho objetiva compreender o padrão de distribuição espacial de um povoamento de Cabralea canjerana em Floresta Estacional Decidual no seu estágio inicial de regeneração natural.

\section{Material e métodos}

A pesquisa foi realizada em uma área do Município de Silveira Martins, na região central do Rio Grande do Sul, inserida na região fitofisionômica conhecida por Floresta Estacional Decidual. O clima da região segundo a classificação de Köppen é do tipo Cfa, caracterizado como subtropical úmido, podendo chegar até $1.700 \mathrm{~mm}$ de precipitação anual (Moreno, 1961). No passado, a floresta que existia na área foi cortada para fins de cultivo de videiras. Com o cessar da vitivinicultura, o local passou a ser utilizado para pastoreio e com o abandono da atividade pecuária, anos depois, foi sendo repovoado por espécies pioneiras.

Para o levantamento dos dados, foram alocadas 77 parcelas contínuas de $5 \mathrm{~m} \times 5 \mathrm{~m}$, totalizando $1.925 \mathrm{~m}^{2} \mathrm{de}$ área amostrada, onde todos os indivíduos de Cabralea canjerana com altura maior ou igual a $30 \mathrm{~cm}$ foram amostrados, medindo-se a altura total com trena. Os mesmos foram organizados em classes de altura, sendo elas: classes I: $30 \mathrm{~cm} \leq \mathrm{h} \leq 100 \mathrm{~cm}$; classe II: $101 \mathrm{~cm}$ $\leq \mathrm{h} \leq 200 \mathrm{~cm}$; classe III: $201 \mathrm{~cm} \leq \mathrm{h} \leq 300 \mathrm{~cm}$ e classe IV: $\mathrm{h} \geq 301 \mathrm{~cm}$ e cap $\leq 15 \mathrm{~cm}$.
A distribuição espacial foi avaliada pelos índices de Morisita (1962), Payandeh (1970) e Fracker \& Brischle (1944). As fórmulas utilizadas para o cálculo dos índices e seus parâmetros para a determinação do modo de dispersão de Cabralea canjerana são apresentados na Tabela 1.

Para avaliar a regeneração natural da espécie no fragmento e analisar a capacidade de resiliência de Cabralea canjerana no local, foram utilizados parâmetros estruturais como densidade e frequência para a espécie, meios considerados por Rodrigues (1999) como parâmetros satisfatórios para avaliação da regeneração natural. Os parâmetros dominância, valor de importância e valor de cobertura não foram calculados devido ao fato deste estudo não ter levado em consideração a área basal dos indivíduos mensurados.

Segundo Daubenmire (1968), a densidade refere-se ao total de indivíduos de uma espécie por unidade de área ou volume, sendo que a densidade absoluta remete ao número de indivíduos por hectare. Neste trabalho, a densidade foi calculada pela equação 1 .

$\mathrm{Da}=\frac{\mathrm{ni}}{\mathrm{A}}$

Onde: $\mathrm{Da}=$ densidade absoluta por espécie; $\mathrm{ni}=$ número total de indivíduos da espécie; A = área total do estudo, em hectares.

A relação entre o número de parcelas que a espécie ocorre e o número total de parcelas determina a frequência da espécie na área. A frequência absoluta para a espécie de estudo foi calculada pela equação 2 .

$\mathrm{Fa}=\frac{\mathrm{Ui}}{\mathrm{Ut}} * 100$

Onde: $\mathrm{Fa}=$ frequência absoluta por espécie; $\mathrm{Ui}=$ número de parcelas que a espécie ocorre; $U t=$ número total de parcelas analisadas.

\section{Resultados e discussão}

\section{Estrutura da população}

Foram mensurados 285 indivíduos de Cabralea canjerana com altura maior ou igual a $30 \mathrm{~cm}$. A média de altura destes indivíduos foi de $1,17 \mathrm{~m}$, sendo a densidade absoluta de 1.481 indivíduos ha-1 .

A frequência absoluta observada para a espécie foi de $91 \%$, uma que vez que a canjerana esteve presente em 70 das 77 parcelas. Em estudo realizado na Floresta Estacional Semidecidual na região de Londrina, Paraná, Silva (1990), encontrou para este parâmetro valores de $88 \%$ para a mesma espécie. Rode et al. (2010) 
encontraram o valor máximo de $100 \%$ para a frequência absoluta de Cabralea canjerana em estudo na Floresta Ombrófila Mista, sendo considerada com alta capacidade de estabelecimento, ratificando a importância desta espécie para a estrutura da floresta. De forma vantajosa, os altos valores de frequência absoluta indicam que a espécie possui alta plasticidade em diferentes condições de sítio (Rode et al., 2010).

Tabela 1. Índices de dispersão utilizados para a análise de distribuição espacial de Cabralea canjerana (Vell.) Mart. em área de regeneração natural da Floresta Estacional Decidual, no Município de Silveira Martins, RS.

\begin{tabular}{|c|c|c|c|}
\hline $\begin{array}{l}\text { Índice de } \\
\text { dispersão }\end{array}$ & Fórmula utilizada & Valores para o índice & Tipo de agregação \\
\hline \multirow{3}{*}{ Morisita } & \multirow{3}{*}{$I=N \frac{\sum X^{2}-\sum X}{\left(\sum X\right)^{2}-\sum X}$} & $\mathrm{I}<1$ & Regular \\
\hline & & $I=1$ & Aleatória \\
\hline & & $\mathrm{I}>1$ & Agregada \\
\hline \multirow{3}{*}{ Payandeh } & \multirow{3}{*}{$P=\frac{S^{2}}{m}$} & $\mathrm{P}<1$ & Aleatória \\
\hline & & $1<\mathrm{P}<1,5$ & Tendência à agregação \\
\hline & & $P>1,5$ & Agregada \\
\hline \multirow{3}{*}{$\begin{array}{c}\text { Fracker \& } \\
\text { Brischle }\end{array}$} & \multirow{3}{*}{$K i=\frac{D i-d i}{d i^{2}}$} & $\mathrm{Ki}<0,15$ & Aleatória \\
\hline & & $0,15<\mathrm{Ki}<1$ & Tendência à agregação \\
\hline & & $\mathrm{Ki}>1$ & Agregada \\
\hline
\end{tabular}

Onde: $\mathrm{I}=$ Valor calculado para o índice de Morisita; $\mathrm{N}=$ número de unidades amostrais; $\mathrm{X}=$ número de indivíduos encontrados em cada unidade amostral; $\mathrm{P}=$ Valor calculado para o índice de Payandeh, $\mathrm{S}^{2}=$ variância amostral; $\mathrm{m}=$ média amostral; Ki = Valor calculado para o índice de Fracker \& Brischle; Di = densidade observada; $\mathrm{di}=$ densidade esperada.

Em relação à distribuição dos indivíduos, pode-se observar um maior número de indivíduos nas menores classes de tamanho, sendo que as duas primeiras classes (até $200 \mathrm{~cm}$ de altura) englobam cerca de $60 \%$ dos indivíduos amostrados na área (Figura 1). É comum a estrutura das florestas nativas serem representadas por uma curva em forma de " $J$ " invertido. O grande número de indivíduos de C. canjerana nas classes de menor tamanho demonstra que há poucos anos as perturbações foram cessadas e aos poucos a espécie está promovendo a recuperação da área. Tal distribuição é característica de florestas nativas multiâneas e indica que a regeneração está ocorrendo de forma contínua (Machado et al., 2009). Estudando a estrutura dimensional de uma floresta estacional semidecidual, Coraiola \& Péllico Netto (2003), também encontraram um padrão de distribuição diamétrica do tipo exponencial negativa para Cabralea canjerana, com grande presença de indivíduos nas classes de menor tamanho.

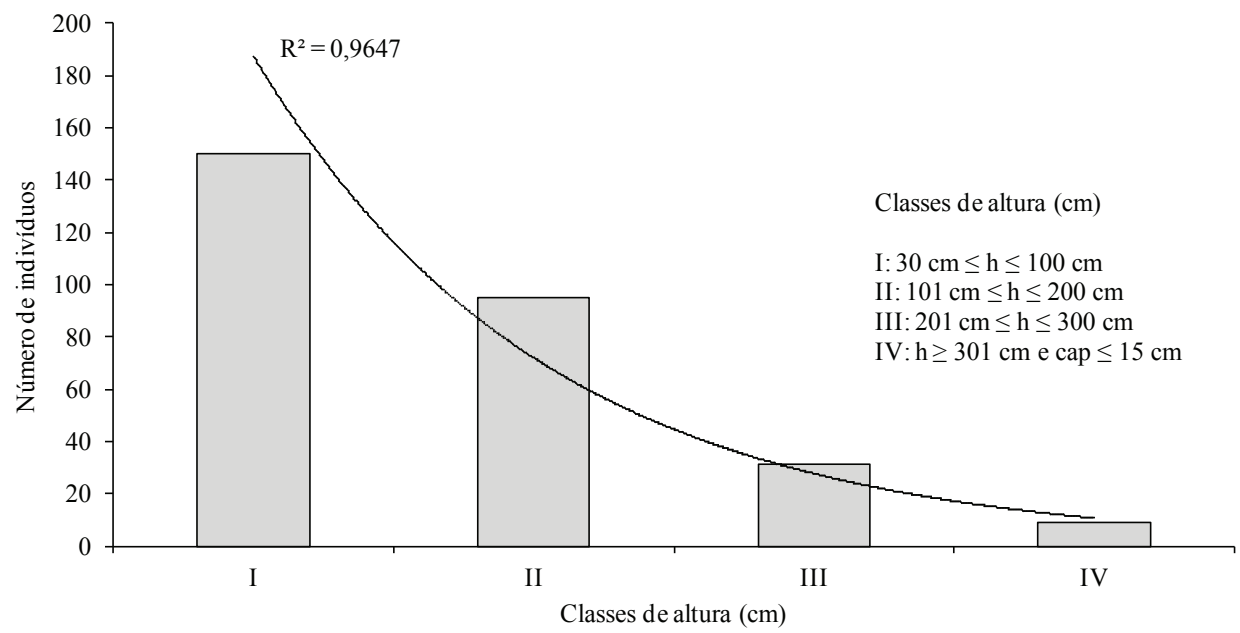

Figura 1. Histograma da distribuição de alturas de uma população de regeneração natural de Cabralea canjerana em área de fragmento de Floresta Estacional Decidual, Silveira Martins, RS. 
Para Santana et al. (2011), a interpretação de histogramas de frequência é de suma importância, pois mostra a situação atual do povoamento e pode ainda indicar possíveis perturbações passadas que tenham ocorrido na floresta. Um elevado número de indivíduos pequenos e finos pode indicar que o povoamento sofreu perturbações num passado recente, como incêndios, ataques de pragas e exploração madeireira (Nunes et al., 2003).

\section{Padrão de distribuição espacial da espécie no local}

Todos os índices de dispersão calculados mostraram que a Cabralea canjerana encontra-se dispersa de maneira agregada na área (Tabela 2).

Tabela 2. Padrões de dispersão para a espécie Cabralea canjerana (Vell.) Mart. em área de regeneração natural da Floresta Estacional Decidual, no Município de Silveira Martins, RS.

\begin{tabular}{ccccc}
\hline \multicolumn{2}{c}{ Parâmetro } & \multicolumn{3}{c}{ Índice de dispersão } \\
\hline $\mathrm{N}$ & $\begin{array}{c}\mathrm{N}^{\circ} \mathrm{de} \\
\text { parcelas }\end{array}$ & Morisita & Payandeh & $\begin{array}{c}\text { Fracker e } \\
\text { Brischle }\end{array}$ \\
\hline 285 & 77 & 1,87 & 4,26 & 71,40 \\
\hline Padrão de dispersão & Agregado & Agregado & Agregado \\
\hline
\end{tabular}

O padrão de dispersão agregrado já era esperado para a espécie, considerando o valor encontrado para a densidade da mesma. Embora a espécie tenha sido observada em $90 \%$ das parcelas, Cabralea canjerana caracteriza-se por formar pequenas manchas em algumas parcelas. Este fato pode estar ligado ao hábito de dispersão zoocórico da espécie e pela presença de poleiros para as aves dispersoras (Carvalho, 1994).

Para Janzen (1988), o padrão de distribuição agregado pode ser explicado pela distância de dispersão das sementes, estando diretamente ligado ao tipo de dispersão que a espécie possui. Cabralea canjerana possui dispersão do tipo zoocórica e segundo Carvalho (1994), o arilo de cor alaranjada serve como atrativo aos pássaros, principalmente os da família Tyrannidade (Pizo, 1997). Embora os pássaros possam ser dispersores eficientes, podendo carregar as sementes a longas distâncias, Pizo (1997) ressalta que, pelo fato da Cabralea canjerana apresentar sementes de tamanho médio, a rápida passagem no trato digestivo das aves faz com que estas sejam descartadas próximas à planta-mãe. Esta é uma hipótese a ser considerada no local de estudo, uma vez que as possíveis plantas-mãe estão a poucos metros da área analisada, que pode ser considerada como rota de voo das árvores dispersoras da espécie. Espécies zoocóricas, como é o caso da Cabralea canjerana geralmente se apresentam de forma agrupada pelo fato de suas sementes serem liberadas sob ninhos ou ao longo de rotas de animais frugívoros (Schupp et al., 2002).

A agregação durante a fase de regeneração é normal para diversas espécies. Para Hutchings (1997) o padrão de distribuição quase sempre agrupado para a fase de regeneração das espécies deve-se ao fato das sementes caírem também de forma agrupada da planta-mãe. No local de estudo não se pode considerar plantas-mãe, mas sim outras árvores que se estabeleceram anteriormente à Cabralea canjerana e serviram como "poleiros" para pássaros que acabaram depositando as sementes trazidas das matrizes ao redor destes indivíduos, conferindo padrão agrupado para a espécie no local.

\section{Conclusão}

De acordo com os índices de dispersão calculados, Cabralea canjerana encontra-se dispersa de forma agregada na área de estudo. Fatores como a presença de poleiros, hábito dos dispersores, bem como a fase a qual o povoamento se encontra, contribuíram para a agregação da espécie.

A distribuição de altura no padrão exponencial negativo, com grande número de indivíduos na menor classe de tamanho, demonstra que a espécie está se regenerando continuamente no local, demonstrando sua importância para a estrutura da floresta.

\section{Referências}

ANJOS, A.; COUTO, H. T. Z.; REIS, A. Análise do efeito de um manejo em regime de rendimento sustentável sobre o padrão de distribuição espacial do palmiteiro (Euterpe edulis Martius), utilizando a função K de Ripley. Revista Árvore, Viçosa, MG, v. 22, n. 2, p. 215-225, 1998.

BACKES, P.; IRGANG, B. Árvores do sul: guia de identificação e interesse ecológico. Porto Alegre: Paisagem do Sul, 2002. 332 p.

CAPRETZ, R. L. Análise dos padrões espaciais de arvores em quatro formações florestais do Estado de São Paulo, através de análises de segunda ordem, como a função K de Ripley. 2004. 79 f. Dissertação (Mestrado em Ecologia de Agroecossistemas) - Escola Superior de Agricultura Luiz de Queiroz, Piracicaba.

CARVALHO, P. E. R. Espécies florestais brasileiras: recomendações silviculturais, potencialidades e uso da madeira. Colombo: EMBRAPA-CNPF; Brasília, DF: EMBRAPA-SPI, 1994. 639 p.

COOMES, D. A.; REES, M.; TURNBULL, L. Identifying aggregation and association in fully mapped spatial data. Ecology, Oxford, v. 80, p. 554-565, 1999. 
CORAIOLA, M.; PÉLLICO NETTO, S. Análise da estrutura horizontal de uma Floresta Estacional Semidecidual localizada no município de Cássia - MG. Revista Acadêmica: Ciências Agrárias e Ambientais, Curitiba, v. 1, n. 2, p. 11-19, abr./jun. 2003.

DAUBENMIRE, R. Plant communities. New York: Harper \& Row, $1968.300 \mathrm{p}$.

FRACKER, S.; BRISCHLE. H. Measuring the local distribution of shrubs. Ecology, Oxford, v. 25, 283-303, 1944.

HUTCHINGS, M. J. The structure of plant population. In: CRAWLEY, M. J. Plant ecology. Boston: Blackwell Scientific Publications, 1997.

JANZEN, D. H. Management of habitat fragments in a tropical dry forest: Growth. Annals of the Missouri Botany Garden, Concord, v. 75, p. $105-116,1988$.

LEGENDRE, P.; FORTIN, M. J. Spatial pattern and ecological analysis. Vegetation, Dordrecht, v. 80, p. 107-138, 1989.

MACHADO, S. A.; AUGUSTYNCZIK, A. L. D.; NASCIMENTO, R. G. M. do; FIGURA, M. A.; SILVA, L. C. R. da; MIGUEL, E. P.; TÉO, S. J. Distribuição diamétrica de Araucaria angustifolia (Bert.) O. Ktze. em um fragmento de Floresta Ombrófila Mista. Scientia Agraria, Curitiba, v. 10, n. 2, p. 103-110, 2009.

MORENO, J. A. Clima do Rio Grande do Sul. Porto Alegre: Secretaria da Agricultura, Diretoria de Terras e Colonização, 1961. $41 \mathrm{p}$.

MORISITA, M. $I_{d-}$-index, a measure of dispersion of individuals. Researches on Population Ecology, Tokyo, v. 4, n. 1, p. 1-7, 1962.

NUNES, Y. R. F.; MENDONÇA, A. V. R.; BOTEZELLI, L.; MACHADO, E. L. M.; OLIVEIRA FILHO, A. T. Variações da fisionomia da comunidade arbóreos em um fragmento de Floresta Semidecidual em Lavras, MG. Acta Botânica Brasílica, Porto Alegre, v. 17, n. 2, p. 213-229, 2003.

PAYANDEH, B. Comparison of method for assessing spatial distribuition of trees. Forest Science, Lawrence, v. 16, p. 312-317, 1970 .
PIZO, M. A. Seed dispersal and predation in two populations of Cabralea canjerana (Meliaceae) in the Atlantic forest of southeastern Brazil. Journal of Tropical Ecology, Cambridge, v. 13, p. 559-578, 1997.

RAYOL, B. P.; SILVA, M. F. F.; ALVINO, F. O. Dinâmica da regeneração natural de florestas secundárias no município de Capitão Poço, Pará, Brasil. Amazônia: Ciência \& Desenvolvimento, Belém, v. 2, n. 3, jul./dez. 2006.

RODE, R.; FIGUEIREDO FILHO, A.; GALVÃO, F.; MACHADO, S. A. Estrutura horizontal da comunidade arbórea sob um povoamento com Aracucaria angustifolia e uma Floresta Ombrófila Mista. Pesquisa Florestal Brasileira, Colombo, v. 30, n. 64, p. 347-361, nov./dez. 2010. DOI: 10.4336/2010.pfb.30.64.347

RODRIGUES, R. R. Restauração de florestas tropicais: indicadores de avaliação e monitoramento vegetal. In: SIMPÓSIO SOBRE RESTAURAÇÃO ECOLÓGICADE ECOSSISTEMAS NATURAIS, Piracicaba. Anais... Piracicaba: Universidade de São Paulo/ESALQ/ Departamento de Ciências Florestais, 1999. p. 8.

SANTANA, J. A. S.; VIEIRA, F. A.; PACHECO, M. V.; OLIVEIRA, P. R. S. Padrão de distribuição e estrutura diamétrica de Caesalpinia pyramidalis Tul. (Catingueira) na Caatinga do Seridó. Revista de Biologia e Ciências da Terra, v. 11, n. 1, 2011.

SCHUPP, E. W.; MILLERON, T.; RUSSO, S. E. Dissemination limitation and the origin and maintenance of species-rich tropical forests. In: LEVEY, D. J.; SILVA, W. R.; GALETTI, M. Seed dispersal and frugivory: ecology, ecolution and conservation. New York: CAB International, 2002. p. 19-33.

SCHÜSSLER, G. Estrutura e dinâmica populacional e aspectos da regeneração natural de Cabralea canjerana (Vell.) Mart. (Meliaceae), em Florestas Ombrófilas Montanas do Planalto das Araucárias, RS. 2006. 90 f. Dissertação (Mestrado em Ecologia) - Instituto de Biociências, Universidade Federal do Rio Grande do Sul, Porto Alegre.

SILVA, S. L. H. Fitossociologia arbórea da porção norte do Parque Estadual Mata Godoy, Londrina - PR. 1990. 197 f. Dissertação (Mestrado em Engenharia Florestal) - Universidade Federal do Paraná, Curitiba. 
